
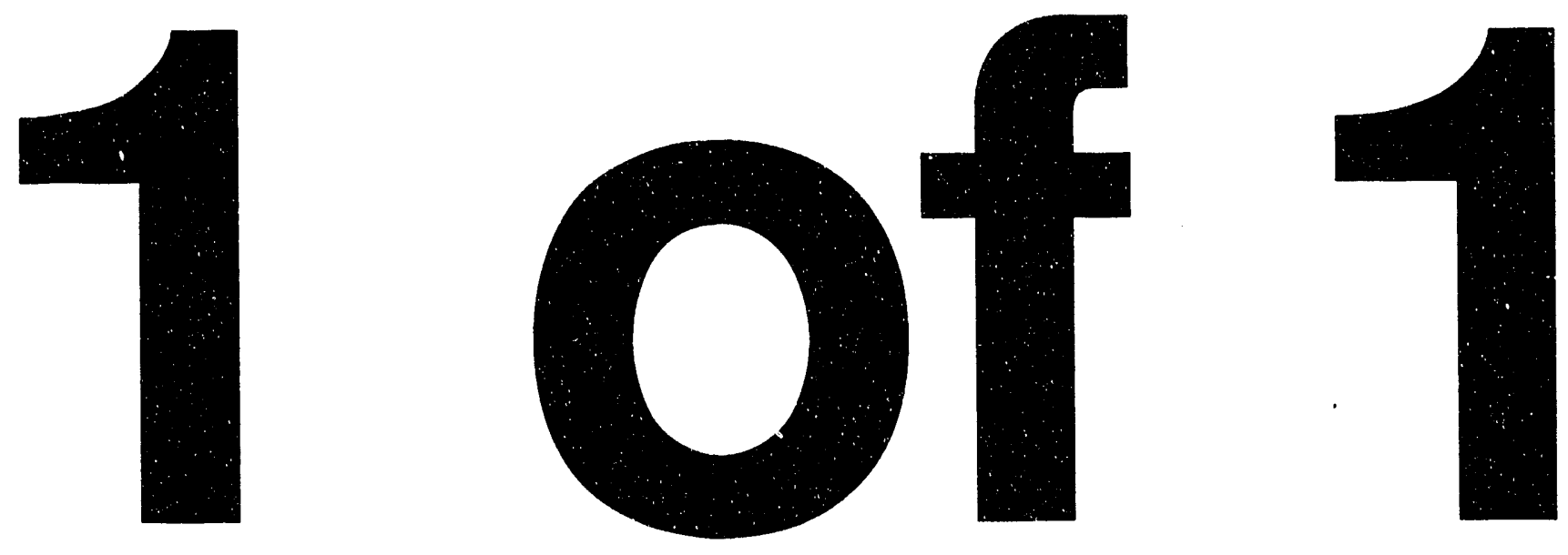


\title{
ADVANCED HEAT PUMP CYCLE
}

to

\section{Ed Fadullon}

U.S. Department of Energy

Office of Placement and Administration

1000 Independence Ave, S.W.

Washington, DC 20585

\author{
from
}

E. A. Groll and R. Radermacher

Department of Mechanical Engineering

Center for Environmental Energy Engineering

The University of Maryland

College Park, MD 20742-3035

July 1993 


\section{TABLE OF CONTENTS}

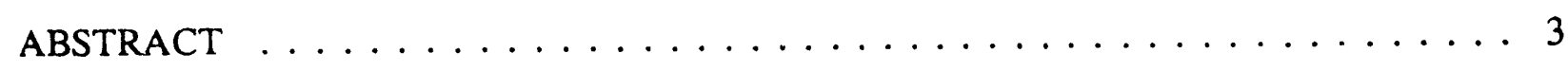

1.0 INTRODUCTION $\ldots \ldots \ldots \ldots \ldots \ldots \ldots \ldots \ldots \ldots \ldots \ldots \ldots \ldots \ldots$

2.0 VAPOR COMPRESSION CYCLE WTTH SOLUTION CIRCUIT $\ldots \ldots \ldots$

3.0 DAHX-CYCLE (DESORBER/ABSORBER HEAT EXCHANGE) $\ldots \ldots \ldots$

4.0 WORKING FLUIDS $\ldots \ldots \ldots \ldots \ldots \ldots \ldots \ldots \ldots \ldots \ldots \ldots \ldots \ldots$

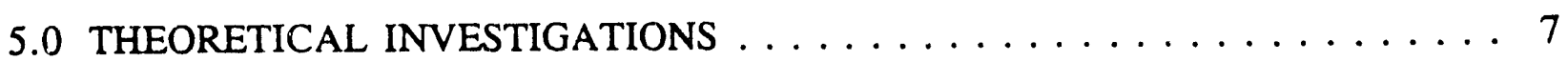

5.1 Calculation Procedure $\ldots \ldots \ldots \ldots \ldots \ldots \ldots \ldots \ldots \ldots \ldots \ldots \ldots \ldots$

5.2 Simulation Results $\ldots \ldots \ldots \ldots \ldots \ldots \ldots$

6.0 EXPERIMENTAL INVESTIGATIONS . . . . . . . . . . . . . . . . 10

6.1 Experimental Plant and Measuring $\ldots \ldots \ldots \ldots \ldots$

6.2 Experimental Results ........................ 11

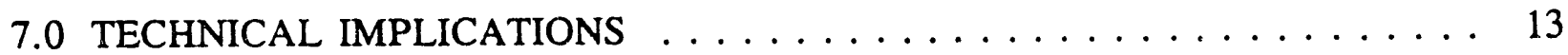

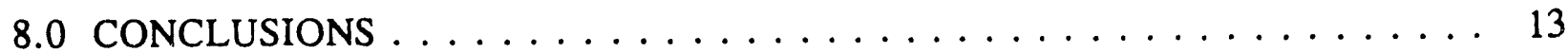

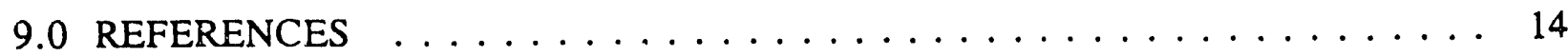

\section{DISCLAIMER}

This report was prepared as an account of work sponsored by an agency of the United States This report was prepared as an accountes Government nor any agency thereof, nor any of their employees, makes any warranty, express or implied, or assumes any legal liability or responsibility for the accuracy, completeness, or usefulness of any information, apparatus, product, or process disciosed, or represents that its use would not infringe privately owned rights. Referprocess disciosed, or represents that its use would not infringe privately owned rights. Refermanufacturer, or otherwise does not necessarily constitute or imply its endorsement, recommanufacturer, or otherwise does not necessarily constitute or imply its endorseren. The views and opinions of authors expressed herein do not necessarily state or reflect those of the United States Government or any agency thereof. 


\title{
ADVANCED HEAT PUMP CYCLE
}

\begin{abstract}
The desorption and absorption process of a vapor compression heat pump with a solution circuit (VCHSC) proceeds at gliding temperature intervals, which can be adjusted over a wide range. In case that the gliding temperature intervals in the desorber and the absorber overlap, a modification of the VCHSC employing a desorber/absorber heat exchange (DAHX) can be introduced, which results in an extreme reduction of the pressure ratio. Although the DAHXcycle has features of a two-stage cycle, it still requires only one solution pump, one separator and one compressor.

Such a cycle for the working pair ammonia/water is built in the Energy Laboratory of the Center for Environmental Energy Engineering at the University of Maryland. The experimental results obtained with the research plant will be discussed and compared to those calculated with a simulation program. The possible temperature lift between heat source and heat sink depending on the achievable COP will be presented.
\end{abstract}




\subsection{INTRODUCTION}

Vapor compression heat pumps with solution circuits have been known in the literature for about 100 years [1]. The first theoretical investigations were carried out by Altenkirch [2] and indicated a large energy savings potential. Based on this potential and the additional need to replace the ozon depleting CFCs, the research activities toward the VCHSC have increased rapidly during the last 10 to 15 years and several different experimental plants were build $[3, \ldots, 14]$.

The VCHSC is a combination of absorption and compression cycle, which employs a working fluid mixtures consisting of a refrigerant and an absorbent, instead of pure components. The refrigerant and the absorbent are characterised by a large boiling point difference. The evaporation of the mixtures is not complete so that the fluid leaving the desorber (comparable to the evaporator in a compression cycle) is a vapor/liquid mixture. Vapor and liquid are separated at the desorber outlet. While the vapor proceeds to the mechanically driven compressor, the liquid is recirculated to the absorber (comparable to the condenser in a compression cycle) with a solution pump in a separate liquid line.

In general vapor compression cycles with solution circuits show the following advantages as compared to conventional compression cycles, which have been discussed in the literature:

1. Increased COP by utilizing the gliding temperatures in desorber and absorber $[4,5,6,8,9$, $15,16]$.

2. Capacity control by varying the concentration of the working fluid mixture $[5,15,17]$.

3. Reduction of the saturation pressures of the pure refrigerants at a given temperature due to the solution in the refrigerant cycle, which allows the resorption temperaturt: of the mixture to be higher than the critical temperature of the pure refrigerant [14].

While point 1 . and 2 . lead to energy savings, point 3 . increases the number of working fluids applicable in VCHSCs. Further energy savings can be obtained by modifying the cycle. E. g., the modification with a two stage solution circuil can lead to a major reduction of the pressure ratio (up to $45 \%$ compared to the pressure ratio of cycles with pure refrigerants) for a given temperature lift. With this technique a single stage compressor can achieve a major increase in 
temperature lift and/or a reciprocating compressor can operate at higher volumetric efficencies $[10,12]$.

In this report another modification of vapor compression cycles with solution circuits employing a desorber/absorber heat exchange and the working fluid ammonia/water is discussed. It will be shown that a further reduction of the pressure ratio can be achieved by applying this cycle. However, in all cases any decrease in pressure ratio is accompanied by an increase in mass flow rate through the compressor as required by thermodynamics [18].

\subsection{VAPOR COMPRESSION CYCLE WITH SOLUTION CIRCUIT}

The main difference between the conventional compression cycle and the one employed here is the usage of a mixture of working fluids with a large boiling point difference instead of a pure fluid. By introducing such a mixture two important features are accomplished:

First, although desorption and absorption occur at constant pressures, the saturation temperatures are no longer constant but vary with the composition changes of the liquid and the vapor phases which occur during the phase change processes. This results in the so-called 'gliding temperature intervals'. These temperature glides can be adjusted over a wide range or, if desired, eliminated almost completely, when the requirement that all the liquid in the evaporator has to evaporate, is eliminated. The remaining liquid portion at the desorber outlet is separated from the vapor and circulated to the absorber by means of a solution pump. Figure 1 shows the schematic of such a cycle in a pressure,temperature-diagram so that the relative location of the heat exchangers is indicative of the temperature and pressure levels. As in a conventional compression cycle, there are four main components: desorber (evaporator), compressor, absorber (condenser), and expansion device. In addition to this a second liquid line with a solution pump is provided, circulating the liquid remaining in the desorber into the absorber. Since there are now two liquid streams available, one from the absorber to the desorber and one from the desorber to the absorber, it is advisable to bring them into heat exchange for better performance of the cycle. Possible variations of this cycle have been discussed by Alefeld [19]. 
Second, a change in the overall concentration of the mixture circulating through the cycle results in a change of the vapor pressures and densities at a given temperature and therefore in a change of the capacity of the entire unit. Both of these features, gliding temperatures and capacity control by means of concentration change can be used to increase the overall COP compared to that of conventional compression systems.

A third feature, which results in a significant decrease of the pressure ratio, by exploiting the gliding temperature differences, will be discussed in the next chapter.

\subsection{DAHX-CYCLE (DESORBER/ABSORBER HEAT EXCHANGE)}

Considering the vapor compression cycle with solution circuit shown in Figure 1, one may wonder what happens, if the gliding temperature intervals in the desorber and the absorber approach each other or even overlap, i.e., when the highest desorption temperature becomes higher than the lowest absorption temperature. In this case, a portion of the absorber is able to supply heat to a part of the desorber, resulting in a new cycle, called the DAHX-cycle. Although this cycle requires still only one solution pump, it has a feature of a two-stage cycle, which is the internal heat transfer between the absorber and the desorber. The idea of a desorber/ absorber heat exchange was first mentioned by Altenkirch [20]. The heat for desorption is partially supplied by an outside source and partially by the absorber. Figure 2 shows a schematic of this cycle in a pressure,temperature-diagram.

Once a DAHX-cycle is accomplished, the absorber pressure can be shifted closer to the desorber pressure. This increases the temperature interval in which the internal heat transfer occurs, but simultaneously decreases the pressure ratio significantly. Figure 3 shows a comparison of a vapor compression cycle with solution circuit and a DAHX-cycle for a given temperature lift. As mentioned above, the decrease in pressure ratio leads to more and more vapor evaporating due to internal heat transfer and not due to heat supply from an outside source, causing the mass flow rate through the compressor to increase and the capacity of the external heat exchange to decrease. 


\subsection{WORKING FLUIDS}

DAHX-cycles as well as absorption cycles require a working fluid mixture, consisting of an absorbent and a refrigerant. Both fluids are characterized by a large difference in boiling point in order to cover a large temperature range at a constant pressure just by change of the composition of the mixture. In general most working fluid mixtures which may be used in absorption cycles can also be introduced in DAHX-cycles. However, based on the mechanical compression of the vapor, the thermophysical pisperties of these mixtures must be evaluated under different aspects. That is why so far the working fluids ammonia/water $[3, . ., 9,12,13]$ and ammonia/water- $\operatorname{LiBr}[21,22]$ and the refrigerant R22 with the solutions DEGDME [15] and E181 [10] were mainly investigated in the literature.

In a theoretical investigation it was suggested to use the working fluids R22/R113 in DAHX-cycles [23]. Groll and Kruse carried out experiments with the working fluids R23/DEGDME and $\mathrm{CO}_{2}$ /acetone in a vapor compression cycle with solution circuit [14]. Since the future usage of the refrigerants R22 and R113 will not be possible because of their ozone depletion potential (ODP), and the usage of R23 must be questioned because of its high global warming potential (GWP), the remaining investigated working pairs are ammonia/water, ammonia/water- $\mathrm{LiBr}$ and $\mathrm{CO}_{2}$ /acetone. As there are not many measurements of the thermodynamic properties of the mixture $\mathrm{CO}_{2}$ /acetone and ammonia/water- $\mathrm{LiBr}$ available, the working fluid chosen for this investigation is ammonia/water.

\subsection{THEORETICAL INVESTIGATIONS}

\subsection{Calculation Procedure}

All calculations of the ammonia/water mixture are based on the modification given by Ibrahim and Klein [24] of the equation of state given by Ziegler and Trepp [25]. It allows the calculation of all thermodynamic and caloric properties in the liquid, vapor, and two-phase region. The property subroutine was implemented in a simulation program to calculate the thermodynamic state points of all fluid streams entering and leaving the components according to Figure 2, 
assuming that the fluid leaving the desorber II and the absorber II is saturated. A minimum temperature difference of $5 \mathrm{~K}$ at the pinch point during desorber/absorber heat exchange was maintained throughout all cycle calculations by two iterative steps. First, the temperature profiles for the desorption and the absorption process were calculated to evaluate the pinch point. Second, based on the value of the pinch point the inlet temperature of the absorber II was adjusted. Both steps were repeated until a minimum temperature difference of $5 \mathrm{~K}$ was reached. The input values for the computer program are the desorber I and II outlet temperatures, the concentration of the weak solution leaving the desorber and the volume flow rate through the solution pump. The efficency of the solution pump is set to 0.6 and the volumetric efficiency and the isentropic efficiency of the compressor are assumed to be 0.7 . Further, the displacement of the compressor is specified.

\subsection{Simulation Results}

The performance of the DAHX-cycle has been evaluated for five ammonia concentrations of the weak solution $(10,15,20,25$, and $30 \%)$ at the same desorber II inlet and outlet temperatures of 10 and $50^{\circ} \mathrm{C}$. For each case the solution pump volume flow rate was varied from 0.2 to 1.0 $\mathrm{l} / \mathrm{min}$. The variation of the solution pump volume flow rate results in a variation in the mass flow rate of the weak solution and therefore in a variation of the circulation ratio, which is defined as the mass flow rate of the rich solution divided by the mass flow rate of the vapor.

Figure 4 shows the calculated $\mathrm{COP}_{\mathrm{c}}$ (cooling COP) of the DAHX-cycle at the given temperatures versus the circulation ratio for each case of the concentration of the weak solution. The plotting of the $\mathrm{COP}_{c}$ versus the circulation ratio results in a parabolic curve with a maximum in $\mathrm{COP}_{\mathrm{C}}$ for a certain circulation ratio.

For the further investigation of the DAHX-cycle only the simulation runs with the maximum COP's for each selected ammonia concentration of the weak solution are taken into consideration.

Figure 5 shows the temperature intervals (represented by lines), which are obtained during the absorption process (solid lines) and during the desorption process (dashed lines) versus the ammonia concentration of the weak solution. The length of a line represents the size of the temperature interval, while its location (with regards to the $y$-axis) gives the absolute 
temperatures. It can be observed that the size of the gliding temperature interval of the absorber I increases with higher concentrations of the weak solution, while at the same time the gliding temperature interval of the desorber I decreases. This change is caused by a variation of the heat of absorption with concentration.

Also shown in Figure 5 are the temperature intervals during the internal desorber/absorber heat exchange. While the desorber II inlet and outlet temperatures remain constant, because they are the input parameters, the inlet and outlet temperatures of the absorber II change with concentration. With higher concentrations of the weak solution the temperature difference between the desorber II outlet and the absorber II inlet decreases towards the minimum difference of $5 \mathrm{~K}$, while the temperature difference between the desorber II inlet and the absorber II outlet increases. This means that the absorption process is completed at higher temperatures with higher concentrations. Towards lower concentrations the opposite effect can be observed. The absorption process is now completed at lower temperatures, which means that the temperature difference between desorber II inlet and absorber II outlet decreases towards the minimum difference of $5 \mathrm{~K}$, while the one between desorber II outlet and absorber II inlet increases.

The pinch point of $5 \mathrm{~K}$ occurs during the desorber/absorber heat exchange. With higher concentrations of the weak solution it appears closer to the absorber II inlet, while with lower concentrations it appears closer to the absorber II outlet.

Based on the observations from Figure 5, a certain ammonia concentration of the weak solution can be found, where the logarithmic mean temperature difference (LMTD) between desorber II and absorber II reaches a minimum. Figure 6 shows the LMTD and the COP $_{c}$ versus the ammonia concentration of the weak solution. It can be seen that the minimum LMTD of $7 \mathrm{~K}$ occurs at the same concentration where the maximum $\mathrm{COP}_{\mathrm{c}}$ of 1.94 occurs. For the given desorber II inlet and outlet temperatures of $10^{\circ} \mathrm{C}$ and $50^{\circ} \mathrm{C}$ this concentration of the weak solution is $18 \%$ ammonia in water. The temperature glides in absorber I for this case are from $73^{\circ} \mathrm{C}$ (inlet) to $57^{\circ} \mathrm{C}$ (outlet) and in desorber I from $1^{\circ} \mathrm{C}$ (inlet) to $10^{\circ} \mathrm{C}$ (outlet). The ammonia concentration of the rich solution is $48 \%$, as can be seen in Figure 7.

The $\mathrm{COP}_{\mathrm{C}}$ of a conventional cornpression cycle operating with the refrigerant $\mathrm{NH}_{3}$ or with the refrigerant $\mathrm{R} 22$ at a condensation temperature of $73^{\circ} \mathrm{C}$ and a evaporation temperature of $1^{\circ} \mathrm{C}$ 
would be $1.76\left(\mathrm{NH}_{3}\right)$ or $1.54(\mathrm{R} 22)$. For the given application the $\mathrm{COP}_{\mathrm{c}}$ of the DAHX-cycle is $10 \%$ higher than the one of the conventional ammonia compression cycle and $26 \%$ higher than the one of the conventional R22-cycle. This increase in $\mathrm{COP}_{\mathrm{c}}$ is based on the fact that the DAHX-cycle takes advantage of the available gliding temperature ranges. This is a feature any cycle operating with a fluid mixture uses. For example, the cooling $\mathrm{COP}_{\mathrm{c}}$ of a single stage vapor compression cycle with solution circuit (VCCSC) operating at the given temperature intervals (absorber: $73^{\circ} \mathrm{C}-57^{\circ} \mathrm{C}$ and desorber: $1^{\circ} \mathrm{C}-10^{\circ} \mathrm{C}$ ) and at an ammonia concentration of the rich solution of $50 \%$ would be 1.92 and therefore in the same range than the one of the DAHX-cycle. A comparison of the performance of the different cycles is given in Table 1.

But the DAHX-cycle features another big advantage over the conventional compression cycle and also over the VCCSC, which can be observed by looking at the pressure ratio versus the concentration of the weak solution as shown in Figure 7. The pressure ratio of the DAHXcycle shows a slight decrease with higher concentrations and does not exceed 2.4 in the range investigated here. For comparison, the pressure ratio of the conventional $\mathrm{NH}_{3}-\mathrm{cycle}$ would be 8.0 , the one of the R22-cycle would be 6.3 and the one of the VCCSC would be 8.4. A reduction of the pressure ratio of $70 \%\left(\mathrm{NH}_{3}\right.$-cycie), of $62 \%$ (R22-cycle) and of $71 \%$ (VCCSC) can be achieved by introducing the DAHY-cycle. This may result in a significantly more efficient compression process, which could lead to even higher COP's than the ones of VCCSC's. The more efficient compression process was not taken into consideration for the simulations done in this study. Both the volumetric and the isentropic efficiencies were assumed to be constant at 0.7 . That is why the COP 's of the DAHX-cycle presented here are in the same range than the ones of VCCSC's, which have been proven in experimental plants $[4,5,6,8,9]$ to be higher than the ones of conventional compression cycles.

\subsection{EXPERIMENTAL INVESTIGATIONS}

\subsection{Experimental Plant and Measuring}

An experimental cycle utilizing the working pair ammonia/ water to investigate vapor compression heat pumps with solution circuit and desorber/absorber heat exchange was built in 
the Energy Laboratory of the Center for Environmental Energy Engineering at the University of Maryland. Three main shell and tube heat exchangers are utilized in the system. They are the desorber I $\left(1.895 \mathrm{~m}^{2}\right)$, where heat is picked up from an outside heat source (water/glycol loop), the absorber ${ }^{\top}\left(2.57 \mathrm{~m}^{2}\right)$, where heat is rejected to an outside heat sink (water loop), and the internal heat exchanger $\left(2.57 \mathrm{~m}^{2}\right)$, where the heat rejected in absorber II is picked up in desorber II.

An oil-free, two-stage, reciprocating compressor (Corken WD 390), which has a displacement of $623 \mathrm{l} / \mathrm{min}$ at $800 \mathrm{rpm}$, compresses the refrigerant vapor. A piston pump (CAT Pump 281) recirculates the weak solution. The expansion process is operated by means of a back pressure regulator (TESCOM). The volume of the separator is 251 .

The temperature is measured by means of calibrated thermocouples inside the piping at the inlet and outlet of each component. The pressure is measured utilizing calibrated, electronic pressure transducers at the outlet of absorber I and II and desorber I and II. The power input into the compressor is obtained by measuring the power consumption of the electric motor by means of a watt-hour transducer. Furthermore, the volume flow rates of the weak and rich solution and the water and water/glycol loop is measured utilizing calibrated turbine meters. The mixture composition of the weak and rich solution is determined by drawing $2-5 \mathrm{ml}$ samples and titrating them against $1 \mathrm{~N}$ (normal) $\mathrm{HCl}$ solution. The location for drawing the samples as well as all temperature, pressure, and volume flow rate measuring locations are shown in Figure 8 .

\subsection{Experimental Results}

The experimental plant was filled with $20 \mathrm{~kg}$ of the ammonia/ water mixture at an ammonia concentration of $42 \%$. All measurements were taken during steady state operating conditions.

The first tests were carried out to investigate the suitability of the compressor for its application in a DAHX-cycle. Figure 9 shows the quotient of the calculated and measured compressor power input as a function of the pressure ratio and the suction pressure. It can be seen that the measured power input increases up to $25 \%$ compared to the calculated power input for suction pressures between 2 and 3 bar and up to 50\% for suction pressures between 1 and 2 bar. The difference between measured and calculated power input decreases towards higher 
pressure ratios. For pressure ratios higher than 6 and suction pressures between 2 and 3, the measured power input agrees well with the calculated power input.

Based on these observations, it can be said that the compressor, which has been taken over from a former project, is not suitable for its application in a DAHX-cycle where the pressure ratios are between 2 and 4 and the suction pressures are between 1 and 2 bar. A new, oil lubricated, single-stage compressor will be used in future experiments.

For the further investigation of the experiments, the pressure ratio, ammonia concentration of the weak solution, and the desorber II outlet temperature were held constant to reduce the inflience of the above mentioned compressor losses on the test results.

Figure 10 illustrates the temperature lift between the lowest desorption and the highest absorption temperature as a function of the circulation ratio. For the given pressure ratio of 3.6, the temperature lift increases towards lower circulation ratios and reaches $90 \mathrm{~K}$ at a circulation ratio of 1.9. Primarily, the highest absorption temperature increases after the mixing of weak solution and vapor. This is because the decrease in circulation ratio was caused by a reduction in weak solution mass flow rate, while the mass flow rate of the vapor stayed constant.

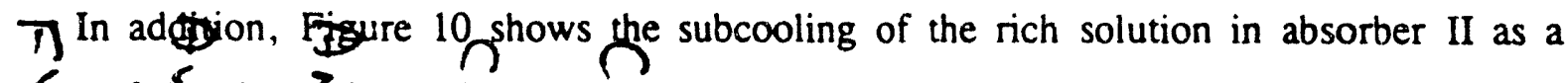

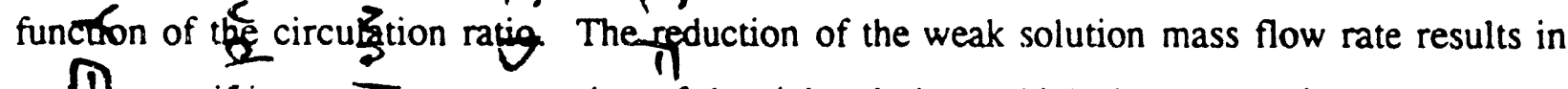
an Increase in ammania conceztrationfor the rich solution, which then results in a decrease of the saturation tempeqpture of the ricte solution and the subcooling at a constant resorption pressure.

Figure 11 indicates the cooling COPs of the same tests as a function of the circulation ratio. In addition, the cooling COPs calculated with an optimized compressor are indicated. Both COPs increase towards lower circulation ratios. This increase is based on the improved internal desorber/absorber heat exchange (decreased subcooling). The highest measured COP was 0.9 for the temperature lift of $90 \mathrm{~K}$. This COP can be raised by $44 \%$ up to a value of 1.3 by utilizing an optimized compressor. 


\subsection{TECHNICAL IMPLICATIONS}

The main advantages of the DAHX-cycle are high COPs at extremely low pressure ratios, which result in low operating costs and open up the application of low cost-low pressure head compressors. The cost of these advantages is the significantly enlarged internal heat transfer area, especially in extreme caser, of very small temperature glides in absorber I and desorber I, and the introduction of a circulation pump. While the power consumption of the pump was found to be below $1 \%$ as compared to the consumption of the compressor and therefore neglectable, the pump itself adds to the first costs of the system. However, the pump may be omitted when the solution is fed into a screw or scroll compressor as shown in Refeience [13].

With respect to the heat transfer area, a rough estimate shows that depending on the gliding temperature intervals and the temperature lift, the area will increase by $50 \%$ up to $100 \%$, as compared to a conventional compression system for a single pure working fluid and water as the heat source and sink fluid. This results in a further increase of the first costs. However, the payback period for a system working with the DAHX-cycle will be in the same range as for a conyentionatgompression system due to the lower operating costs.

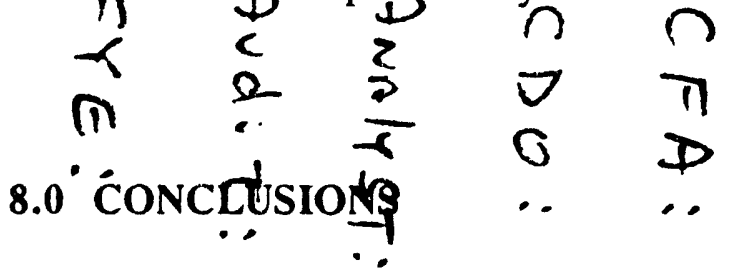

The vapor compression cycle with a solution circuit and a desorber/absorber heat exchange (DAHX-cycle) has been introduced. A computer program to simulate the DAHX-cycle and an experimental facility utilizing the working pair ammonia/water were established. Based on the simulations and the experiments the following conclusions can be drawn:

For a given desorber II temperature interval and ammonia concentration of the weak solution and at a constant compressor volume flow rate, a maximum of the COP depending on the circulation ratio can be found.

By taking the maximum COP for each ammonia concentration of the weak solution and plotting it against this concentration another maximum of the COP can be found, exactly then when the logarithmic mean temperature difference of the interna desorber/ absorber heat 
exchange reaches a minimum.

The cooling COP of the DAHX-cycle is up to $10 \%$ higher than the one of a conventional refrigeration system operating with the refrigerant $\mathrm{NH}_{3}$ and up to $26 \%$ higher than the one of a system operating with $\mathrm{R} 22$, when the same highest and lowest temperatures in the absorber/condenser and the desorber/evaporator were to be achieved.

The pressure ratio of the DAHX-cycle is up to $70 \%$ smaller than the one of the convertional $\mathrm{NH}_{3}$ retrigeration system, up to $62 \%$ smaller than the one of the $\mathrm{R} 22$-cycle, and up to $71 \%$ smaller than the one of a ammonia/water vapor compression cycle with a one stage solution circuit. The pressure ratio reduction can lead to further energy savings of the DAHXcycle because of a more efficient compression process.

- A temperature lift of $90 \mathrm{~K}$ between the highest and lowest temperatures in the absorber and the desorber and a cooling COP of 0.9 were obtained with the experimental plant at a pressure ratio of 3.6 and at a circulation ratio of 1.9 resulting in a $75 \%$ decrease of the pressure ratio compared to a conventional compression cycle operating with pure $\mathrm{NH}_{3}$. The optimization of the compressor for its application in a DAHX-cycle will result in an increase in COP of up to $44 \%$. $D \perp$

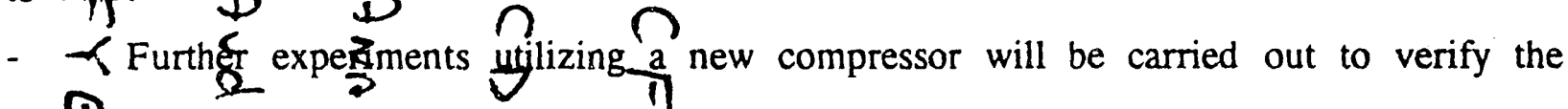
profitsing results of pire simutgtion stydjes.
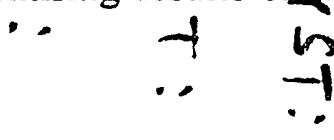

\subsection{REFERENCES}

[1] Osenbrück, A.: Verfahren zur Kälteerzeugung bei Absorptionsmaschinen; Deutsches Reichspatent DRP 84084 (1895)

[2] Altenkirch, E.: Kompressionskältemaschine mit Lösungskreislauf; Kältetechnik, 2 (1950) 10, S. 251-259, 2 (1950) 11, S. 279-284, und 2 (1950) 12, pp. 310-315

[3] Bercescu, $V$. et al.: Aspects du fonctionnement d'une installation expérimentale de pompe de chaleur avec compression mécanique et circulation additionelle de la solution; Proc. of the XVI ${ }^{\text {th }}$ Int. Congress Refrig., Commission E2, Paris, Frankreich (1983), pp. 173-178 
[4] Mucic, V.; Scheuermann, B.: Zwei-Stoff-Kompressions-Wärmepumpe mit Lösungskreislauf; Pilot Plant Mannheim/ Waldhof, BMFT-Forschungsbericht T 84-197 (1984)

[5] Stokar, M.; Trepp, C.: Compression Heat Pump with Solution Circuit, Part 1: Design and Experimental Results; Int. J. Refrig., 10 (1987) 3, pp. 87-96

[6] Malewski, W. F.: Integrated Absorption and Compression Heat Pump Cycle using mixed Working Fluid Ammonia and Water; Proc. of the 2nd Int. Workshop on Research Activities on Advanced Heat Pumps, Graz, September (1988)

[7] Mučić, V.: Resorption Compressions Heat Pump with Solution Circuit for Steam Generation using Waste Heat of Industry Heat Source; Newsletter of the IEA Heat Pump Center, 7 (1989) 1, pp. 14-15

[8] Rane, M.V.; Radermacher, $\mathbb{R}$; Herold, K. E.: Experimental Investigation of a Single Stage Vapor Compression Heat Pump with Solution Circuit; Proc. of the ASME Winter Annual Meeting, Advances in Industrial Heat Pump Technology, AES Vol. 8 (1989), pp. $41-45$

[9] Bergmann, G.; Hivessy, G.: Experimental Hybrid Heat Pump of $1000 \mathrm{~kW}$ Heating Capacity; Proc. of the 4th Int. Conf. on Application and Efficiency of Heat Pump Systems, 01.-03. Oct., Munich (1990). sti, Oxford

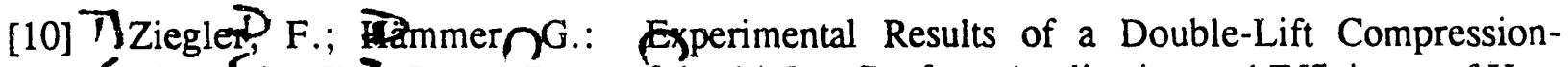
K Absorntion Hect Pump Proc. of the 4th Int. Conf. on Application and Efficiency of Heat (n) Pump Systems $01 .-03$ Oct., Munich (1990). sti, Oxford

[11] Kawada, A. 2 Ptake, M.; Toyofuku, M.: Absorption Compression Heat Pump using TFE/É181; Proc. of Absorption Heat Pump Conf., 30. Sep. - 02. Oct., Tokyo, .apan (1991), pp. $121-126$

[12] Rane, M. V.; Radermacher, R.: Experimental Investigation of Two Stage Vapor Compression Heat Pump with Solution Circuits; Proc. of the XVIII ${ }^{\text {h }}$ Int. Congress Refrig., August 10-17 (1991) Montreal, Quebec, Canada

[13] Torstensson, H.; Nowacki, J.-E.: A Sorption/Compression Heat Pump Using Exhaust Air as Heat Source; Proc. of Absorption Heat Pump Conf., 30. Sep. - 02. Oct., Tokyo, Japan (1991), pp. 103-108

[14] Groll, E.A.; Kruse, H.: Kompressionkältemaschine mit Lösungskreislauf für umweltverträgliche Kältemittel; KK DIE KÄLTE und Klimatechnik, Gentner Verlag Stuttgart, April (1992), pp. 206-218 
[15] Pourreza-Djoursari, S.; Radermacher, R.: Calculation of the Performance of Vapor Compression Heat Pumps with Solution Circuits Using the Mixture R22/DEGDME; Int. J. Refrig., 6 (1986) 9, pp. 245-250

[16] Lotz, H.: Bertiebsverhalten von Ein- und Mehrstoffwärmepumpen; Wärmepumpen, Veröffentlichung der gleichnamigen Tagung in Essen (1977), Vulkan-Verlag Essen, pp. 26-33

[17] Gerdsmeier, K.D.; Kruse, H.: Experimentelle Untersuchungen zur Leistungsregelung mit nichtazeotropen Gemischen; DKV-Tagungsbericht 16. Jahrgang (1989), Hannover, pp. $335-343$

[18] Radermacher, R.: An Example of the Manipulation of Effective Vapor Pressure Curves by Thermodynamic Cycles; J. Eng. for Gas Turbines and Power, 10 (1988) 110, pp. $647-651$

[19] Alefeld, G.: Heat Conversation Systems, Lecture Notes; Technical University of Munich, Physics Department E19, 8046 Garching, Germany (1983)

[20] Altenkirch, E.; Tenckhoff, B.: Absorptionskältemaschine zur kontinuierlichen Erzeugung von Kälte und Wärme oder auch von Arbeit; Deutsches Reich Patent Nr. 278076, (1911)

[21] T] AhlbyDL.; Radermacher, R.; Hpdgett, D.: $\mathrm{NH}_{3} / \mathrm{H}_{2} \mathrm{O}-\mathrm{LiBr}$ as Working Fluid for the $\checkmark$ Compfession/Absorption Cycle; submitted to the Int. J. Refrig. (1992)

[22]. Chatzidakis S.; Qhogdak7s, E.: Das Verhalten der Zwei- und Dreistơffkontpessionskältemaschine mit Lösungskreislauf; KI Klima-Kälte-Heizung 7-8 (1992), S. 255-258

[23] Radermacher, R.: Vapor Compression Heat Pump Cycle with Desorber/Absorber Heat Exchange; Proc. of the XVII ${ }^{\text {th }}$ Int. Congress Refrig., (1986) Vienna, Austria, S. 10611066

[24] Ibrahim, O. M.; Klein, S. A.: Thermodynamic Properties of Ammonia-Water Mixtures; submitted to ASHRAE, January (1992)

[25] Ziegler, B.; Trepp, C.: Equation of State for Ammonia-Water Mixtures; Int. J. Refrig., 2 (1984) 7, S. $101-106$ 
Table 1: Comparison of the DAHX-cycle with a vapor compression cycle with single stage solution circuit and with a conventional compression cycle

\begin{tabular}{|l|l|c|c|c|c|}
\hline Cycle & working Fluid & $\begin{array}{l}\text { Cond./Absor. } \\
\text { Temperature }\end{array}$ & $\begin{array}{l}\text { Evap./Desor. } \\
\text { Temperature }\end{array}$ & PR & COP \\
\hline DAHX & Ammonia/water & $73^{\circ} \mathrm{C} \ldots 57^{\circ} \mathrm{C}$ & $1^{\circ} \mathrm{C} \ldots 10^{\circ} \mathrm{C}$ & 2.4 & 1.94 \\
vCCsC & Ammonia/water & $73^{\circ} \mathrm{C} \ldots 57^{\circ} \mathrm{C}$ & $1^{\circ} \mathrm{C} \ldots 10^{\circ} \mathrm{C}$ & 8.4 & 1.92 \\
CCC & Ammonia & $73^{\circ} \mathrm{C}$ & $1{ }^{\circ} \mathrm{C}$ & 8.0 & 1.76 \\
CCC & R22 & $73^{\circ} \mathrm{C}$ & $1^{\circ} \mathrm{C}$ & 6.3 & 1.54 \\
\hline
\end{tabular}

vccsc: vapor compression cycle with single stage solution circuit CCC: conventional compression cycle

PR: pressure ratio

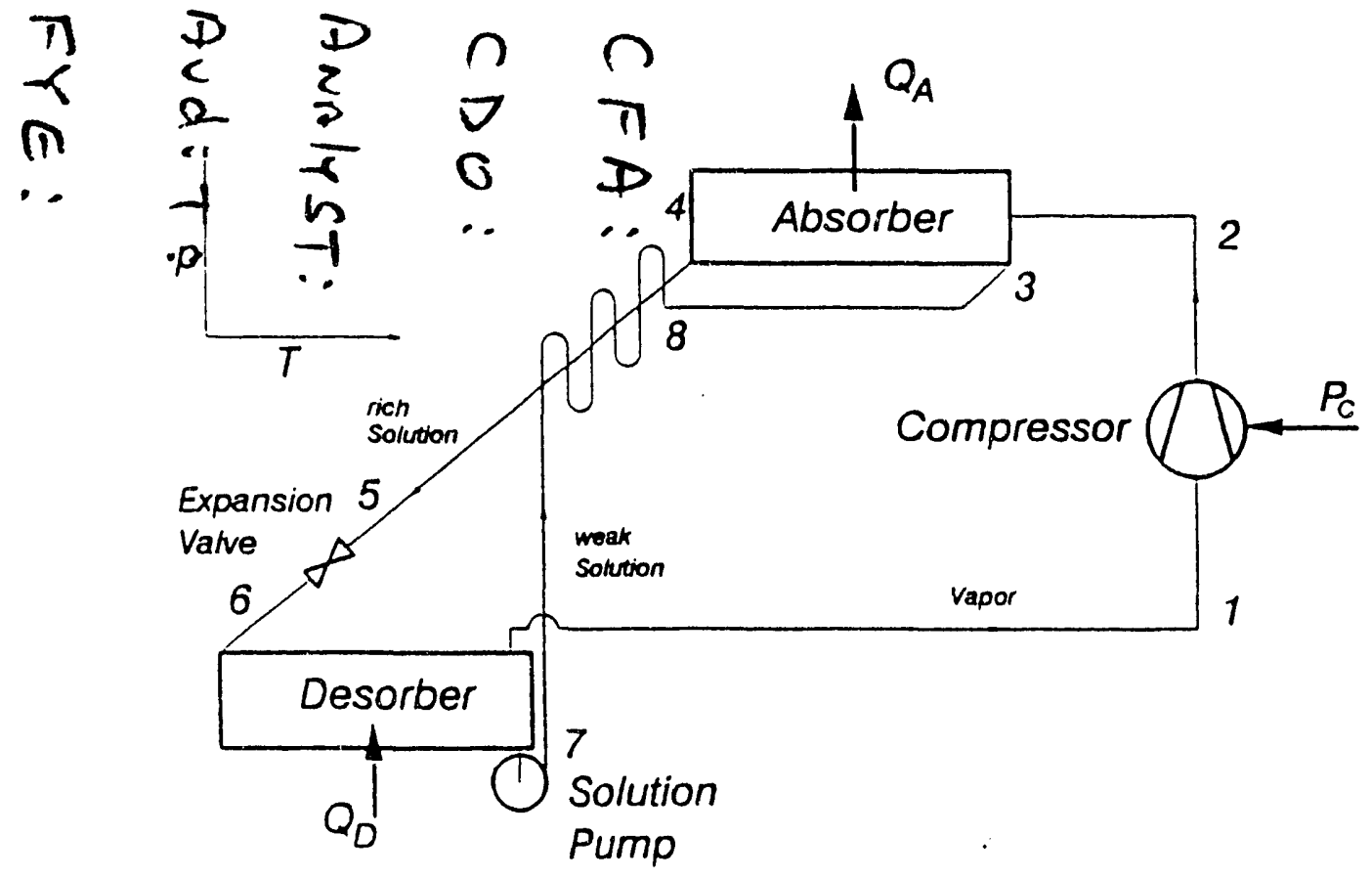

Figure 1: Process scheme of a vapor compression cycle with solution circuit (VCCSC) 


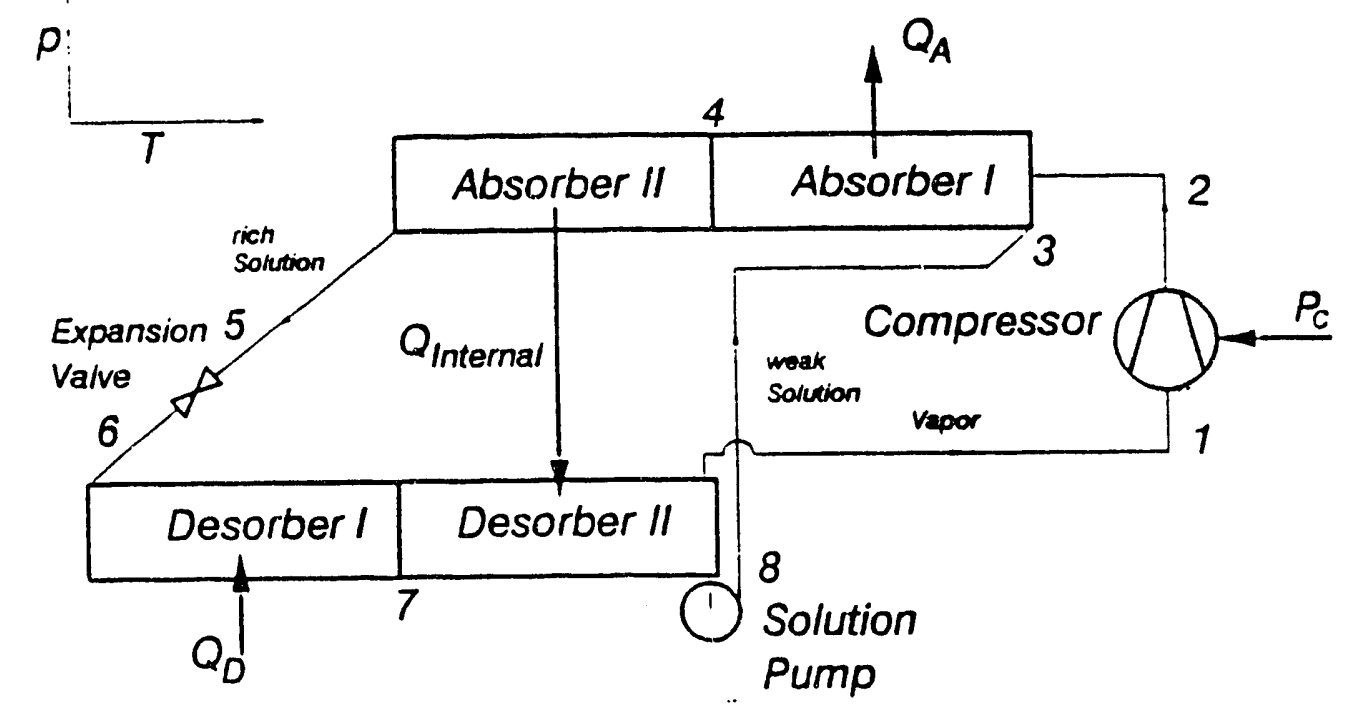

Figure 2: Process scheme of a vapor compression cycle with solution circuit and desorber/absorber heat exchange (DAHX-cycle)

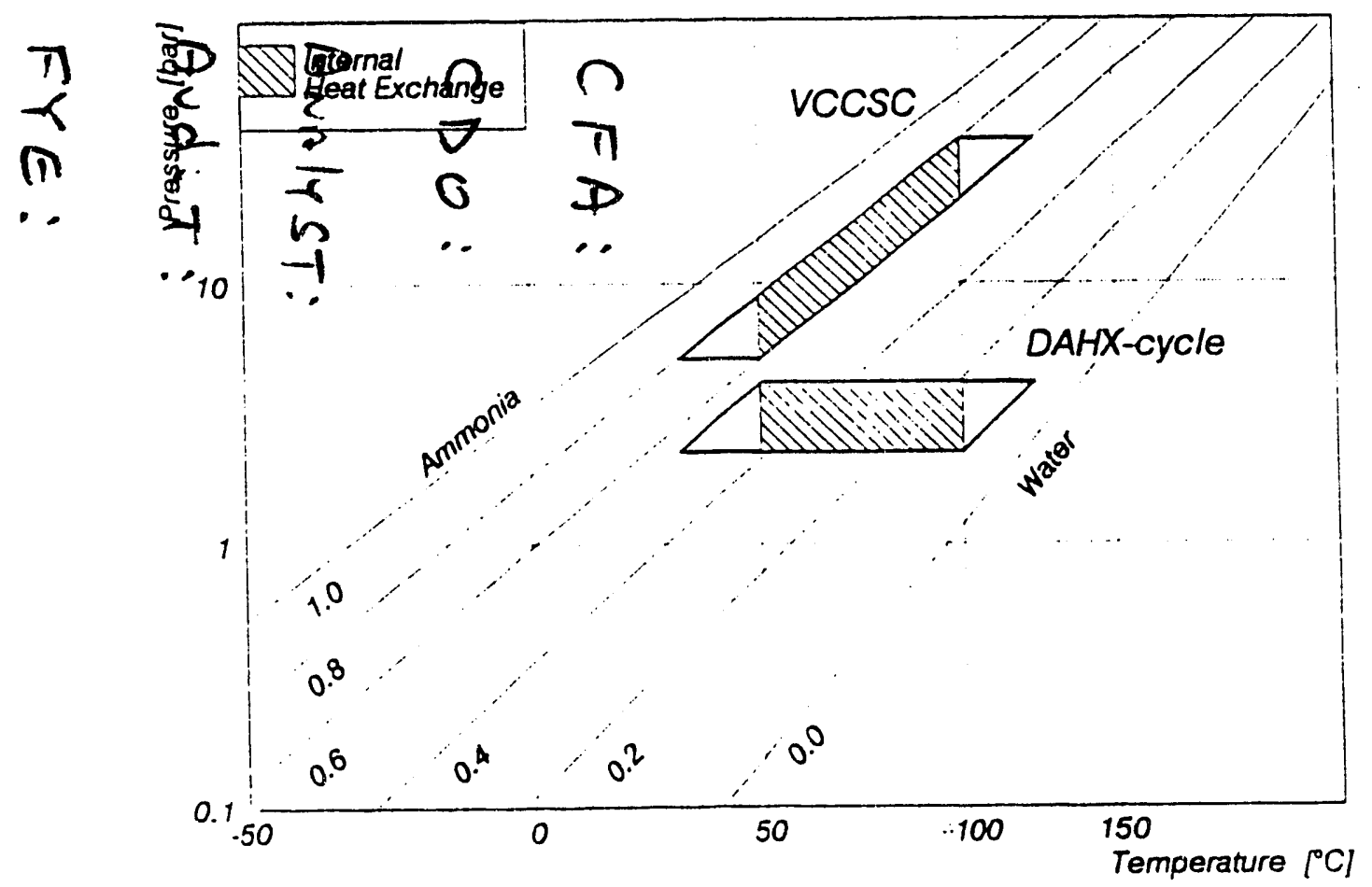

Figure 3: Cycles representing a VCCSC and a DAHX-cycle for the same heat source and sink temperature intervals 


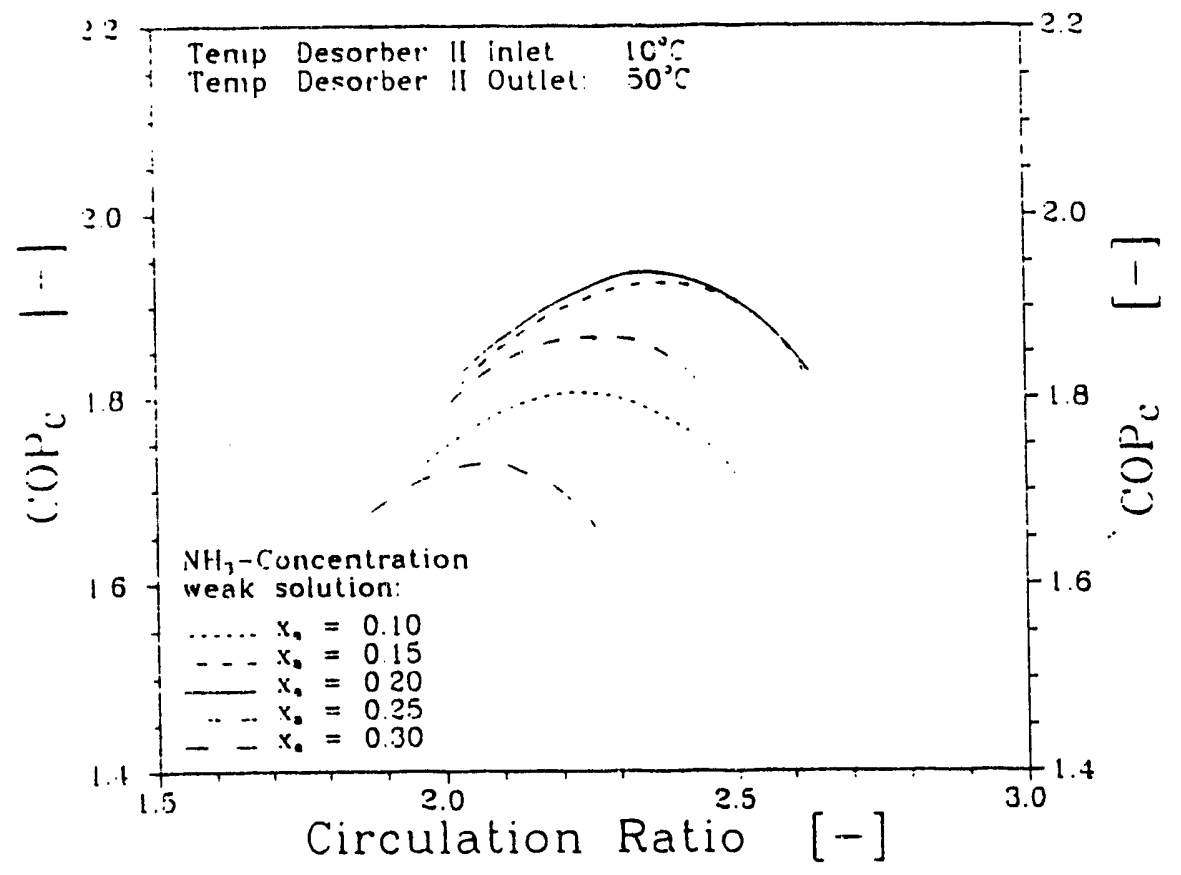

Figure 4: COP cooling versus circulation ratio for five ammonia concentrations of the weak solution

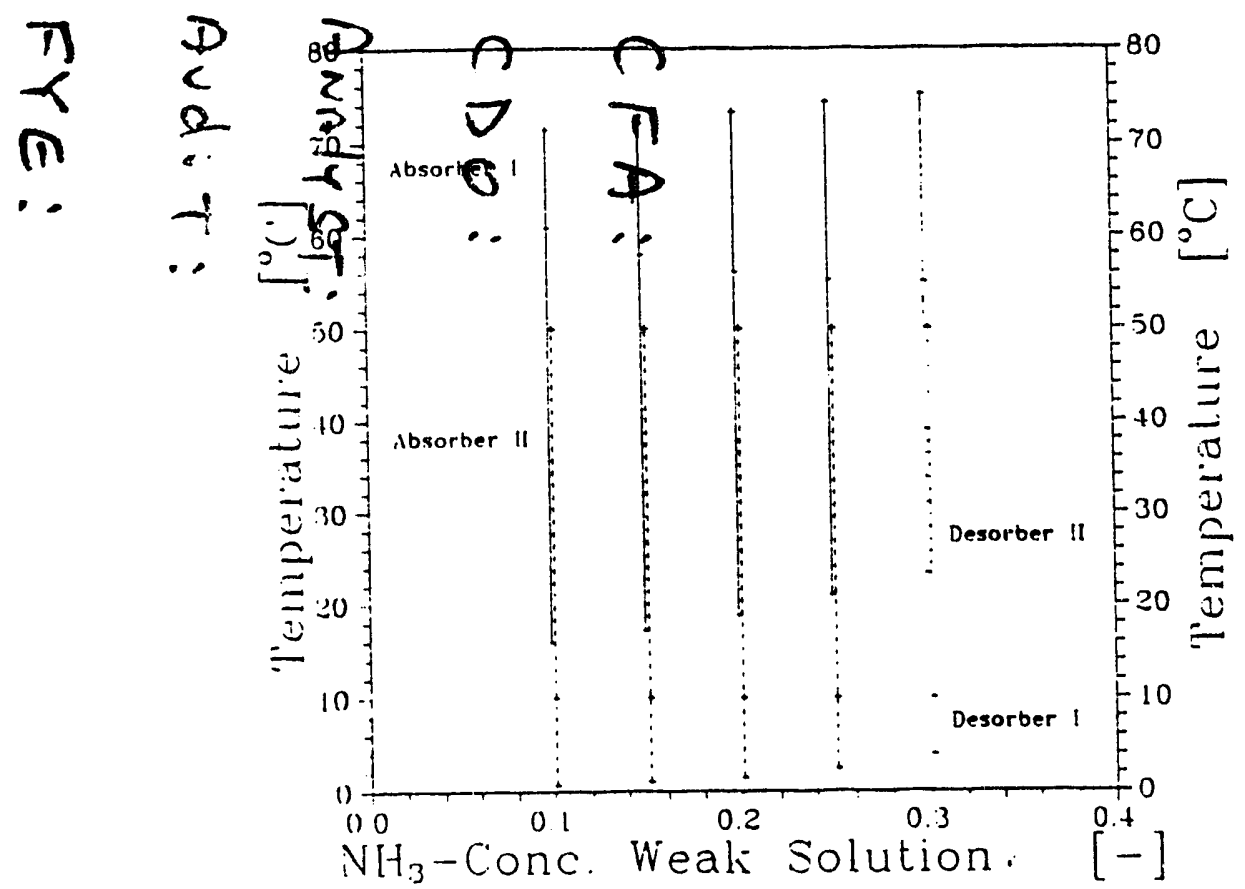

Figure 5: Temperature intervals during absorption and desorption process versus ammonia concentration of the weak solution 


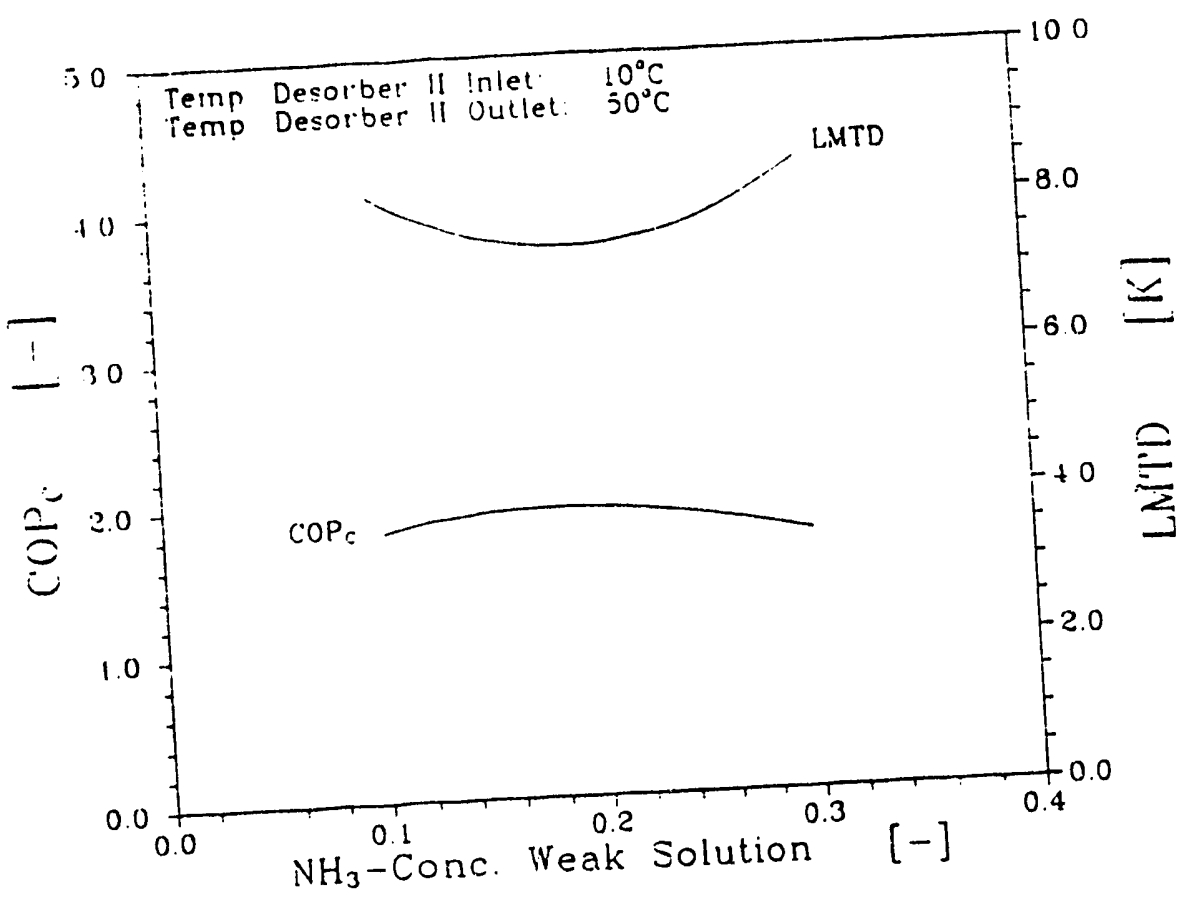
Figure 6: Logarithmic mean temperature difference between absorber II and desor
and COP cooling versus ammonia concentration of the weak solution

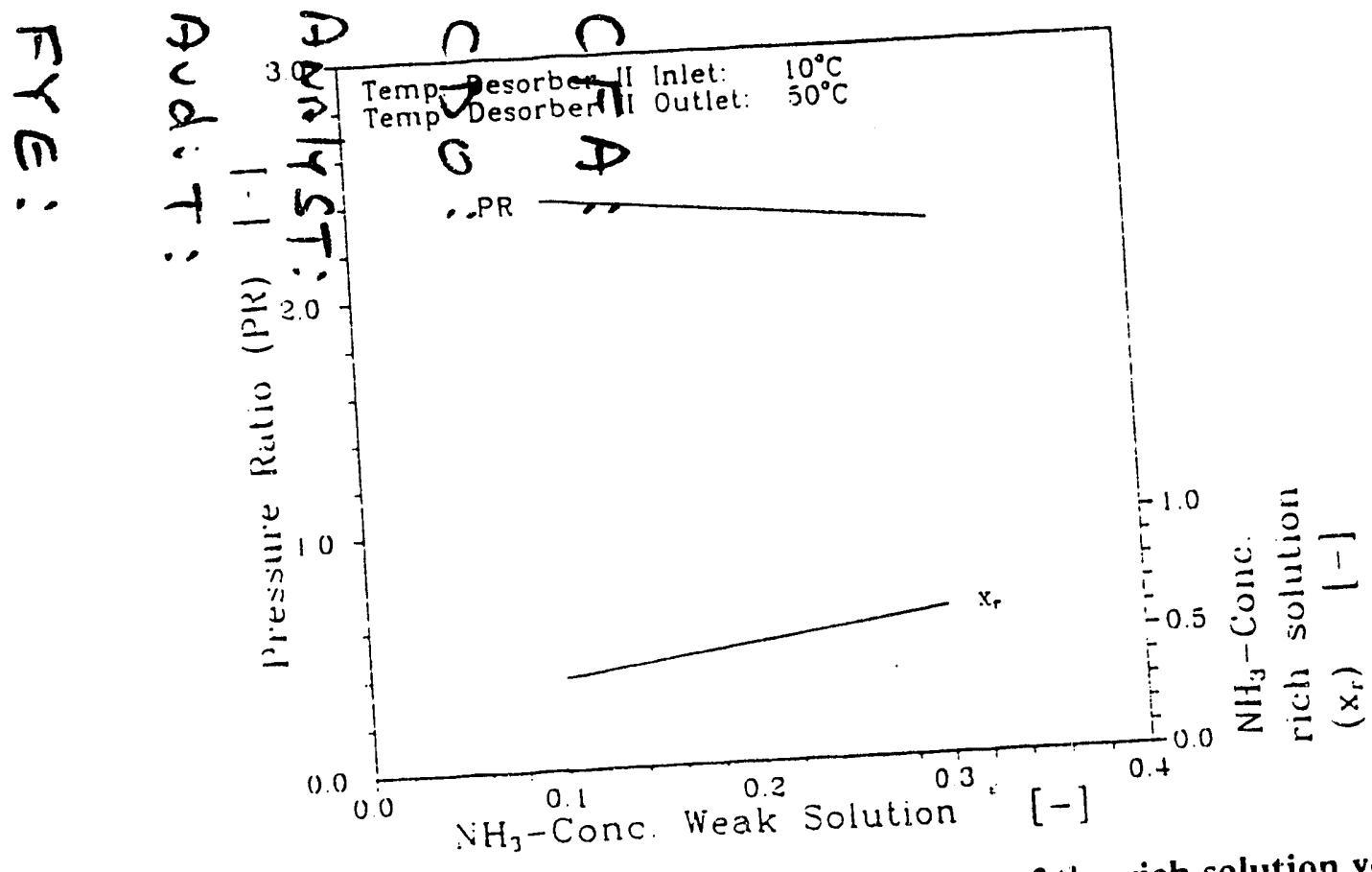

Figure 7: Pressure ratio and ammonia concentration of the rich solution versus ammonia concentration of the weak solution 


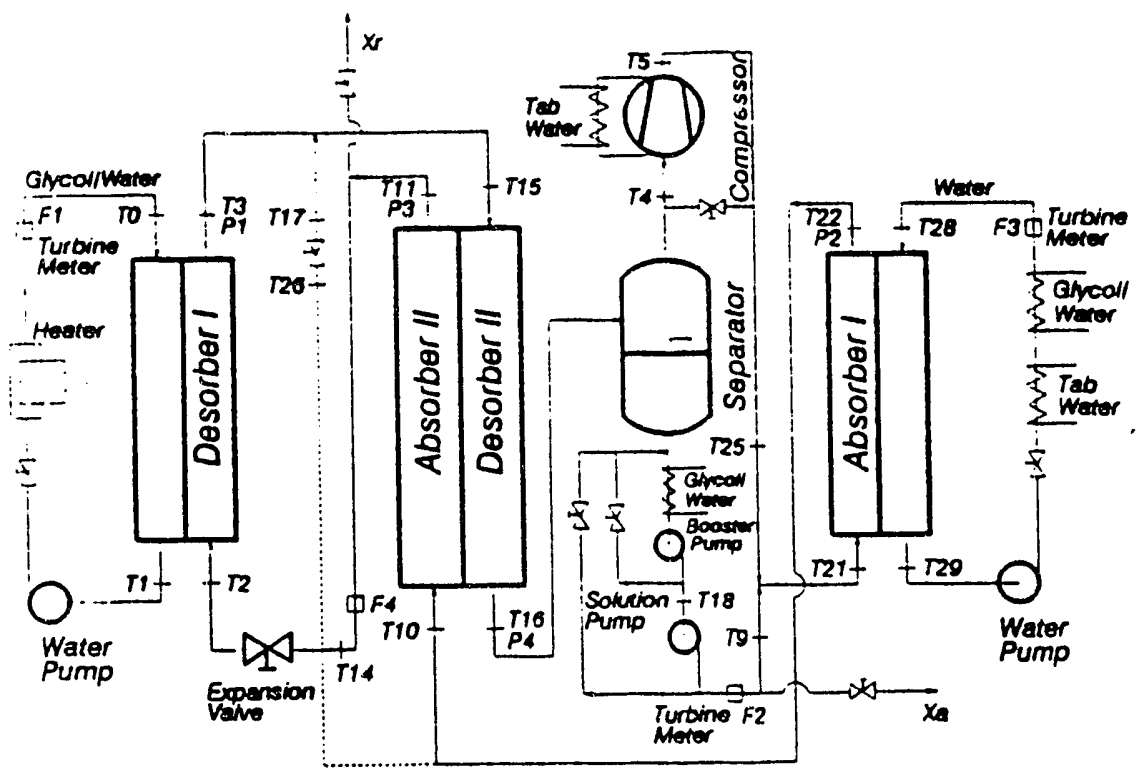

Figure 8: Experimental setup with locations for sample withdraw, temperature, pressure, and volume flow rate measurements

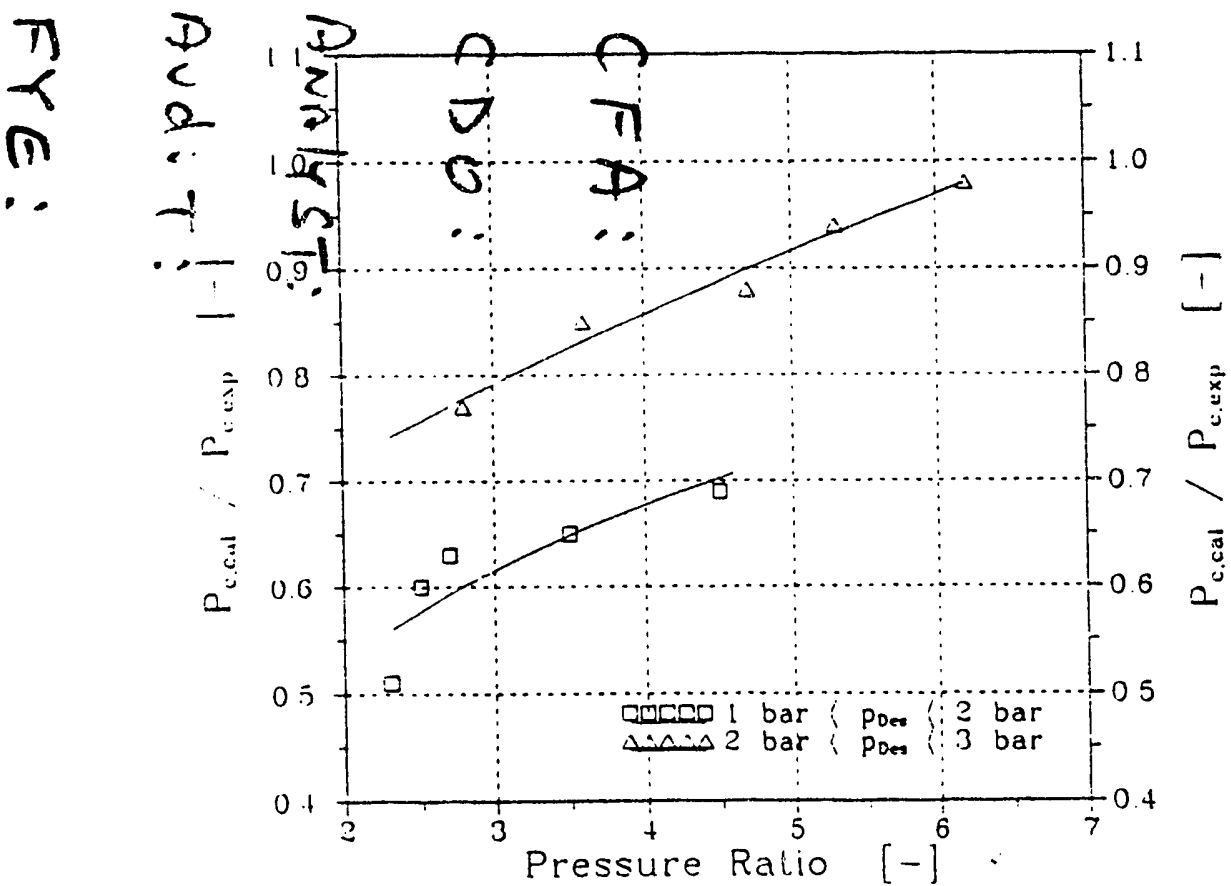

Figure 9: Quotient of the calculated and measured compressor power input versus the pressure ratio 


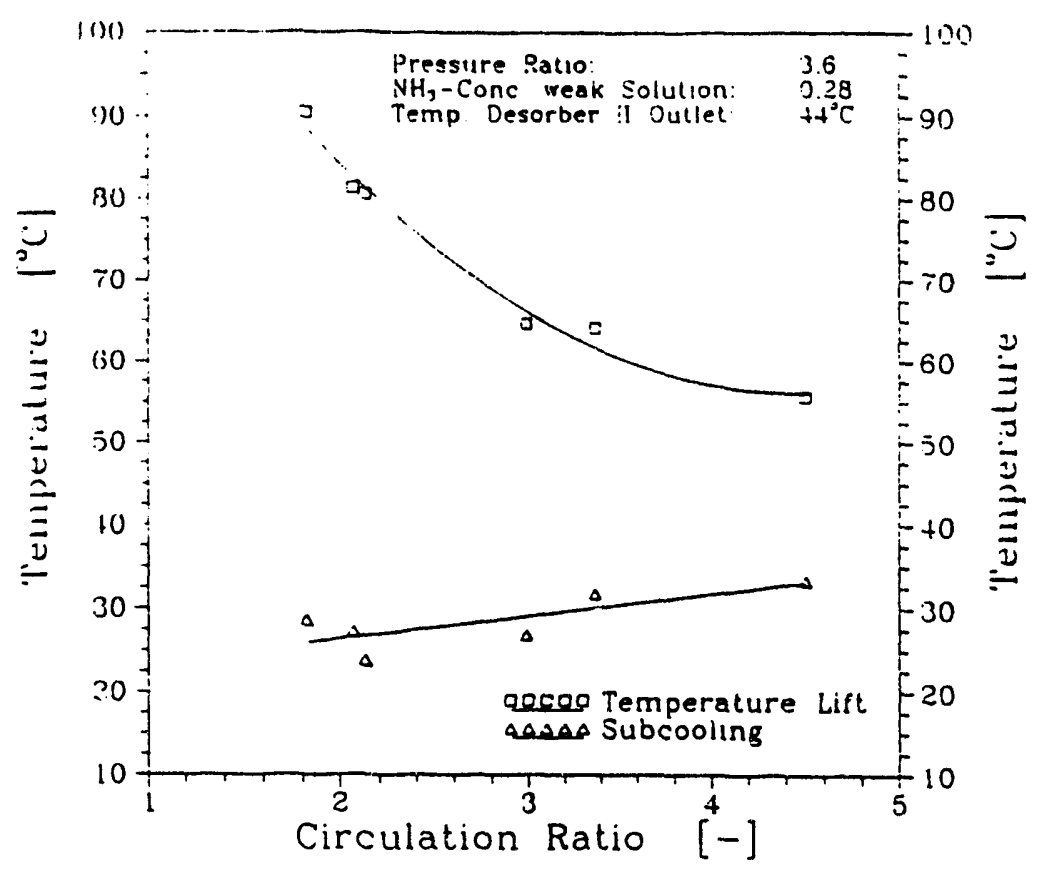

Figure 10: Temperature lift between lowest desorption and highest absorption temperature and subcooling in absorber $\mathbb{I}$ versus the circulation ratio

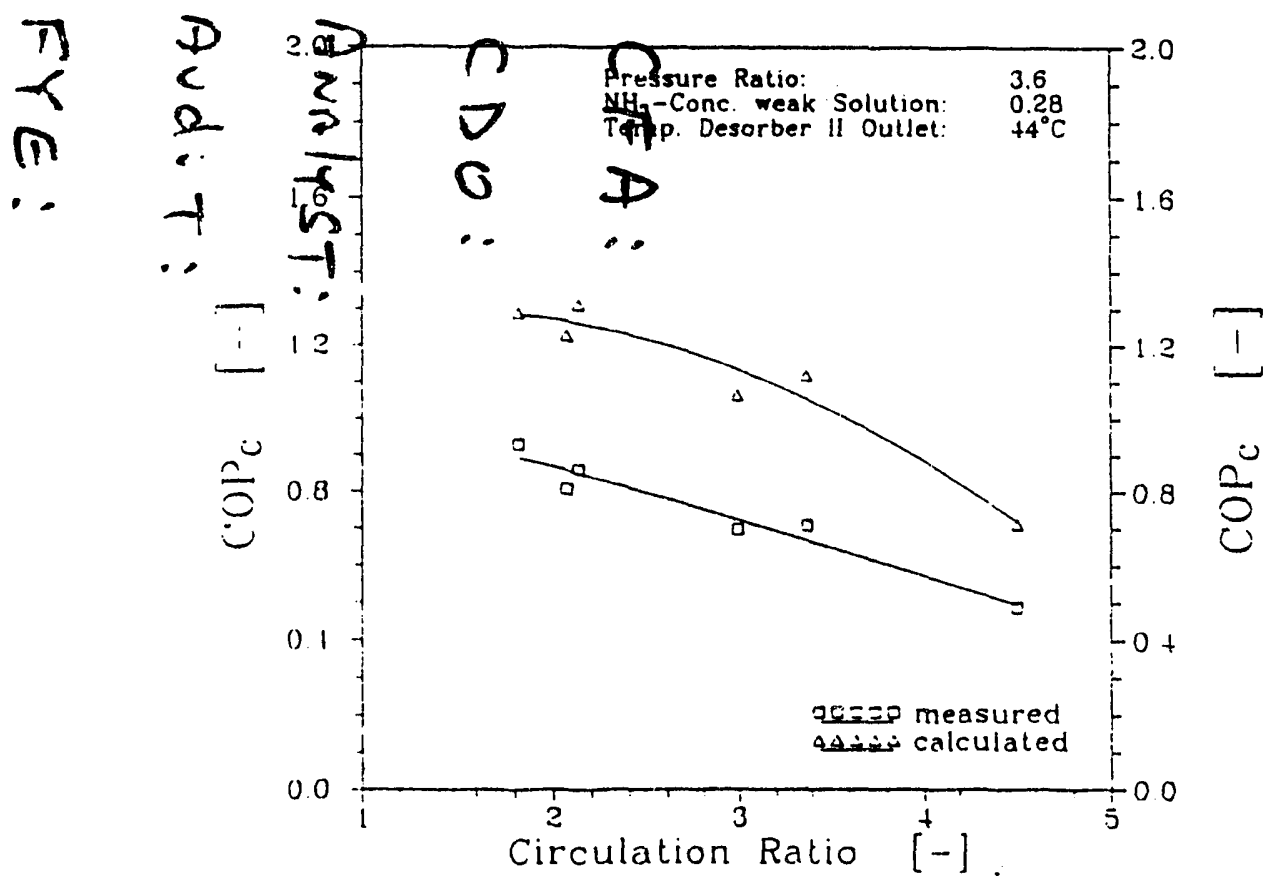

Figure 11: Measured and calculated cooling COP versus the circulation ratio 

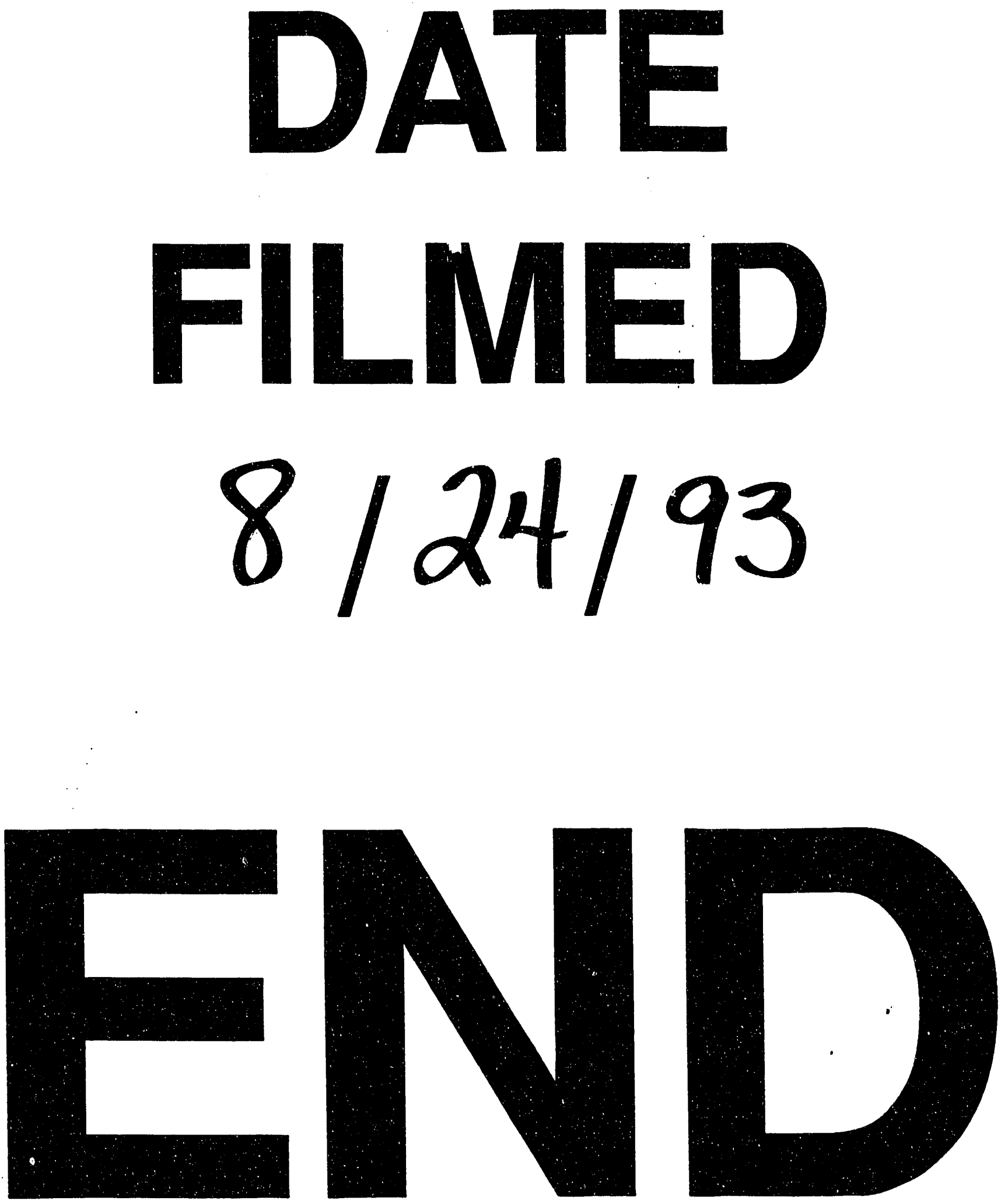
